\title{
HEALTH ANXIETY AND EMOTION REGULATION DURING THE PERIOD OF COVID-19 OUTBREAK IN TURKEY
}

\author{
Derya Canlı ${ }^{1}$ \& Burcu Karaşar ${ }^{2}$ \\ ${ }^{I}$ Department of Psychiatry, Amasya University Sabuncuoğlu Şerefeddin Training and Research Hospital, \\ Amasya, Turkey \\ ${ }^{2}$ Department of Psychological Counselling and Guidance, Amasya University Education Faculty, Amasya, Turkey
}

received: 15.6.2020;

revised: 7.8.2020;

accepted: 23.10 .2020

\begin{abstract}
SUMMARY
Background: The process of COVID-19 outbreak has affected Turkey as it has affected the whole world. The purpose of the current study is to investigate individuals' health anxiety and emotion regulation during the period of COVID-19 outbreak in Turkey in relation to some variables. The study also aims to explore the relationship between emotion regulation and health anxiety.

Subjects and methods: The study was conducted on 874 individuals reached online through the google e-forms. The participants were administered the "Health Anxiety Scale and Emotion Regulation Scale" to collect data. In the analysis of the collected data, Mann- Whitney U Test, Kruskal Wallis-H Test, Spearman Correlation Coefficient were used.

Results: In the current study, healthy anxiety scores of the participants were analyzed depending on some variables. Health anxiety was found to be higher in women, 18-30 age group, singles, students, and groups with physical and mental health problems. The research also found that there is a low and negative relationship between health anxiety and cognitive reappraisal. It is understood that men's suppression scores are higher than women. There is no significant difference between suppressing emotions and health anxiety. It was found that educators received the highest scores in terms of cognitive reappraisal. The cognitive reappraisal level of the group without mental disorder was found to be higher than the other group.

Conclusion: According to the results of the research, more supportive services should be provided for the groups with the higher health anxiety. Considering that especially students and young people are affected more, it can be said that mental health preventive services should be included more in these groups. At the same time, the fact that men have higher emotion suppression scores than women shows that this situation should also be taken into consideration in mental health services.
\end{abstract}

Key words: health anxiety - emotion regulation - COVID-19 outbreak

$* * * * *$

\section{INTRODUCTION}

Coronavirus disease (COVID-19), which occurs in Wuhan, China and spreads all over the world, causes many negative conditions including mental and behavioral reactions and disorders, as well as it poses a serious threat to health and life (Jakovljevic et al. 2020). There is a sudden and big change for the majority of people in the form of home-stay and quarantine, which is unknown how long it will last. Causes such as isolation, social distance, staying away from family and friends, job loss are associated with increased mental risks (Jakovljevic 2020). The COVID-19 pandemic caused mental states such as anxiety and panic (Marčinko et al. 2020). During the course of the outbreak, many people in Turkey have been both physically and psychologically affected. Various studies have been conducted all over the world about the psychological effects of the COVID-19 outbreak (Wang et al. 2020, Mazza et al. 2020, Li et al. 2020, Lee \& You 2020). Especially health anxiety is thought to increase in most people during the epidemic period (Ekiz et al. 2020).

Health anxiety, although there is no physical illness in the person, refers to an excessive interpretation of the usual body sensations towards a disease (Aydemir et al. 2013). In health anxiety, person's perception of a threat related to health triggers anxiety. Occassionally, everyone may have mild health anxiety. However, it becomes a problem when health concerns are excessive, there is no real and serious medical problem and the tests are normal and it disrupts daily functionality (Anderson et al. 2011). Health anxiety is a situation that everyone can experience, but sometimes it can be constant and debilitating. When health anxiety is maladaptive, it is called serious health anxiety and this is associated with various dysfunctional beliefs and health-related control behaviours (Asmundson \& Fergus 2019). In a study by Sunderland et al. (2013), the lifetime prevalence of health anxiety was found to be $5.7 \%$. Kirkpinar et al. (2016) found that health anxiety was observed at a higher level in hypochondriasis compared to somatization disorder. Believing to a sick, anxiety related to the sick and seeking treatment are basic symptoms of hypochondriasis (Ghanizadeh \& Firoozabadi 2012). Ekiz et al. (2020) found that health anxiety was seen moderately in epidemic process in Turkey. Health anxiety is also associated with emotion regulation. There are various studies reporting relationship between health anxiety and emotion regulation (Görgen et al. 2014, Love et al. 2018).

Emotions which are important and basic processes in functions such as adaptation, emergence of targeted behaviours, decision making increase the quality of life 
and functionality of the person if the message they convey is pondered about and can be properly understood (Ceçen 2002). Therefore, emotion regulation is thought to be a life skill that must be learned in the early stages of life (Macklem 2010, Shoutham-Gerow 2013). Emotion regulation is defined as the ability to observe, experience, evaluate and change emotional responses. Emotion regulation involves external processes such as "others" in the interpersonal environment that are responsible for achieving the goal, and internal processes like the person himself/herself (Thompson 1994). It is possible to divide the internal processes in emotion regulation into two as antecedent-focused and responsefocused. The antecedent-focused emotion regulation involves the processes that the person applies before or when the emotion is about to emerge, while response-focused emotion regulation involves the processes of regulation of the emotion after it has emerged (Gross 1998a).

Cognitive reappraisal, which is one of the antecedent-focused emotion regulation methods, is defined as loading a new meaning into a situation that may give rise to an emotional response (Gross \& John 2003). Studies have found that cognitive reappraisal is positively associated with well-being while suppressing emotions is negatively associated with well-being (Gross \& John 2003, Haga et al. 2009). Emotion suppression, which is one of the response-focused emotion regulation methods, is a method that includes efforts to erase emotional experiences and prevent emotional expressions (Gross 1998b). The existing research shows that these two emotion regulation methods are used extensively and are related to the indicators of psychological health (John \& Gross 2004). Studies have shown that there is a relationship between emotion regulation strategies and depression, anxiety, eating disorder, and substance abuse (Aldao et al. 2010, Martin \& Dahlen 2005, Harrison et al. 2010, Joormann \& Gotlib 2010, Omran 2011, D’Avanzato et al. 2013, Hopwood et al. 2015, Ruscitti et al. 2016, Weinbach et al. 2018).

The number of studies examining the relationship between health anxiety and emotion regulation appears to be few. Görgen et al. (2014) reported a significant relationship between health anxiety and emotion regulation.

Due to Coronavirus (COVID-19), which is declared as a pandemia worldwide, many people in our country are affected both physiologically and psychologically. The virus threatens the individual's own health and the health of the people around him/her, leading to sense of fear and anxiety. In this process, an increase in people's health anxiety levels is predictable. The current study is the first study to investigate health anxiety and emotion regulation in relation to some variables in the COVID 19 epidemic period. This study is considered to be important because it is the first study to examine health anxiety and emotion regulation in detail. It is thought that taking the findings of the current study into consideration while planning mental health services during the epidemic is important for public mental health. The aim of this study was to examine emotion regulation and health anxiety in terms of some variables.

\section{SUBJECTS AND METHODS}

A total of 874 individuals reached online from different provinces of Turkey through the google e-forms in April-May 2020 are the participants of the current study. All the participants were administered a Sociodemographic Data Form, the Health Anxiety Scale and Emotion Regulation Questionnaire. In the Socio-demographic Data Form developed by the researchers, there are items to elicit information about gender, age, marital status, education level and occupation.

\section{Psychometric measures}

Emotion Regulation Questionnaire: The questionnaire was developed by Gross \& John (2003). In the validity and reliability studies of the questionnaire conducted by Totan (2015), it was concluded that the original version of the questionnaire was confirmed in the

Table 1. Socio-demographic characteristics of the study group

\begin{tabular}{|c|c|c|}
\hline Variables & $\mathrm{n}$ & $\%$ \\
\hline \multicolumn{3}{|l|}{ Age groups } \\
\hline 18-30 years & 519 & 59.4 \\
\hline $31-40$ years & 181 & 20.7 \\
\hline $41-50$ years & 124 & 14.2 \\
\hline$>51$ years & 50 & 5.7 \\
\hline \multicolumn{3}{|l|}{ Gender } \\
\hline Males & 232 & 26.5 \\
\hline Females & 642 & 73.5 \\
\hline \multicolumn{3}{|l|}{ Marital status } \\
\hline Single & 544 & 62.2 \\
\hline Married & 330 & 37.8 \\
\hline \multicolumn{3}{|l|}{ Education level } \\
\hline Elementary-secondary & 25 & 2.9 \\
\hline High school & 101 & 11.6 \\
\hline Associate's degree & 58 & 6.6 \\
\hline Bachelor's degree & 597 & 68.3 \\
\hline Graduate degree & 93 & 10.6 \\
\hline \multicolumn{3}{|l|}{ Occupation } \\
\hline Student & 331 & 37.9 \\
\hline Healthcare personnel & 187 & 21.4 \\
\hline Educator & 130 & 14.9 \\
\hline Private sector & 111 & 12.7 \\
\hline Public worker & 36 & 4.1 \\
\hline Unemployed-retired & 79 & 9.0 \\
\hline \multicolumn{3}{|l|}{ Health problem } \\
\hline Yes & 131 & 15.0 \\
\hline No & 743 & 85.0 \\
\hline \multicolumn{3}{|l|}{ Mental illness } \\
\hline Yes & 33 & 3.8 \\
\hline No & 841 & 96.2 \\
\hline
\end{tabular}


Turkish culture. The Cronbach alpha values of the questionnaire were found to be as follows: 0.78 for cognitive reappraisal and 0.71 for emotion suppression. Testretest correlation was found to be 0.67 for cognitive reappraisal and .65 for emotion suppression.

Health Anxiety Scale: The scale was developed by Salkovskis et al. (2002) and adapted to Turkish by Aydemir et al. (2013). The Cronbach alpha internal consistency of the scale was found to be 0.91 . The item total score coefficients of the scale were found to be ranging from 0.40 to 0.76 . The test-retest coefficient of the scale was found to be 0.57 . In the construct validity study, the scale was found to be consisted of two sub-dimensions explaining $54.5 \%$ of the total variance. These two subdimensions are excessive sensitivity to bodily symptoms and anxiety about physical illnesses.

\section{Statistical Analysis}

In the analysis of the collected data, IBM SPSS Statistics for Windows 20.0 programme package was used. Mann-Whitney U test and Kruskal Wallis- $\mathrm{H}$ test were used to determine whether health anxiety and emotion regulation vary significantly depending on some variables. In the analysis of the relationship between health anxiety and emotion regulation, Spearman Correlation Analysis was used. Prior to the analyses, whether the data had a normal distribution was tested with Kolmogorow Smirnov test. In the current study, $\mathrm{p}<0.05$ value was accepted to be statistically significant.

The study was approved by Amasya University Social Sciences Ethics Committee (21/04/2020-E.8809) and Provincial Health Directorate.

\section{RESULTS}

A total of 874 individuals (642 (73.5\%) women and $232(26.5 \%)$ men) participated in the current study. Descriptive statistics about the characteristics of the study group are given in Table 1.

The health anxiety scores of the participants were analyzed in relation to different variables. The health anxiety scores were found to be varying significantly depending on gender ( $\mathrm{U}: 56174.50, \mathrm{p}<0.05$ ). When mean ranks were taken into consideration, the mean health anxiety score of the female participants was found to be higher than that of the male participants. The health anxiety scores of the participants were found to be varying significantly depending on age $\left(x^{2}=16.25, \mathrm{p}<0.05\right)$.

Table 2. Evaluation of health anxiety in terms of different variables

\begin{tabular}{|c|c|c|c|c|c|c|c|}
\hline Variables & $\mathrm{n}$ & Mean \pm SD & Median & Min & Max & Mean rank & $p$-value \\
\hline Age groups & & & & & & & 0.00 \\
\hline $18-30$ years & 519 & $16.53 \pm 6.65$ & 16.00 & 1 & 43 & 465.90 & \\
\hline $31-40$ years & 181 & $14.75 \pm 7.18$ & 14.00 & 1 & 41 & 398.12 & \\
\hline $41-50$ years & 124 & $14.89 \pm 7.49$ & 14.00 & 0 & 45 & 395.45 & \\
\hline$>51$ years & 50 & $14.26 \pm 7.28$ & 14.00 & 2 & 35 & 389.54 & \\
\hline Gender & & & & & & 0.00 & \\
\hline Males & 232 & $13.66 \pm 6.56$ & 13.50 & 0 & 41 & 358.63 & \\
\hline Females & 642 & $16.57 \pm 6.95$ & 16.00 & 1 & 45 & 466.00 & \\
\hline Marital status & & & & & & & 0.04 \\
\hline Single & 544 & $16.15 \pm 6.71$ & 15.00 & 1 & 43 & 451.14 & \\
\hline Married & 330 & $15.23 \pm 7.35$ & 15.00 & 0 & 45 & 415.01 & \\
\hline Education level & & & & & & & 0.07 \\
\hline Elementary-secondary & 25 & $19.88 \pm 8.83$ & 20.00 & 4 & 45 & 561.86 & \\
\hline High school & 101 & $15.91 \pm 8.70$ & 15.00 & 0 & 44 & 429.71 & \\
\hline Associate's degree & 58 & $16.46 \pm 7.17$ & 16.00 & 3 & 30 & 459.13 & \\
\hline Bachelor's degree & 597 & $15.73 \pm 6.61$ & 15.00 & 1 & 41 & 437.30 & \\
\hline Graduate degree & 93 & $14.61 \pm 6.08$ & 14.00 & 2 & 41 & 400.32 & \\
\hline Occupation & & & & & & & 0.04 \\
\hline Student & 331 & $16.32 \pm 5.97$ & 16.00 & 3 & 39 & 464.07 & \\
\hline Healthcare personnel & 187 & $16.01 \pm 7.08$ & 16.00 & 1 & 44 & 447.61 & \\
\hline Educator & 130 & $14.75 \pm 6.78$ & 14.00 & 2 & 41 & 399.21 & \\
\hline Private sector & 111 & $14.73 \pm 7.63$ & 14.00 & 1 & 41 & 390.18 & \\
\hline Public worker & 36 & $13.44 \pm 6.96$ & 12.00 & 2 & 29 & 346.31 & \\
\hline Unemployed-retired & 79 & $17.44 \pm 9.13$ & 16.00 & 0 & 45 & 473.32 & \\
\hline Health Problem & & & & & & & 0.02 \\
\hline Yes & 131 & $17.35 \pm 7.99$ & 16.00 & 0 & 44 & 482.34 & \\
\hline No & 743 & $15.53 \pm 6.74$ & 15.00 & 1 & 45 & 429.59 & \\
\hline Mental illness & & & & & & & 0.00 \\
\hline Yes & 33 & $21.45 \pm 8.72$ & 21.00 & 10 & 41 & 598.88 & \\
\hline No & 841 & $15.58 \pm 6.80$ & 15.00 & 0 & 45 & 431.17 & \\
\hline
\end{tabular}

SD - Standard Deviation 
According to the mean ranks, the highest mean health anxiety score was found to belong to the participants in the age group of 18-30, followed by the age group of 31-40 and 41-50. The health anxiety scores were also found to be varying significantly depending on marital status (U: $82339.50, \mathrm{p}<0.05$ ) and the mean rank of the single participants was found to be higher than that of the married participants. The health anxiety scores were found to be not varying significantly depending on education level $\left(x^{2}=8.62, \mathrm{p}>0.05\right)$. The health anxiety scores were found to be varying significantly depending on profession $\left(x^{2}=17.18, \mathrm{p}<0.05\right)$ and the students' healthy anxiety were found to be significantly higher than educators, private sector and public workers. A significant difference was also found between the groups having health problems and not having health problems (U: 42793.00, $\mathrm{p}<0.05$ ); the mean health anxiety score of the participants having health problems was found to be higher. A significant difference was found between the participants having mental disorders and not having metal disorders ( $\mathrm{U}: 8551.00, \mathrm{p}<0.05$ ); the participants having mental disorders were found to have a higher mean health anxiety score. Results are presented in Table 2.
In the analyses conducted to determine whether cognitive reappraisal scores vary significantly depending on some variables, it was found that cognitive cognitive reappraisal scores vary significantly depending on occupation $\left(x^{2}=18.14, \mathrm{p}<0.05\right)$. The educators cognitive reap- praisal scores were found to have be higher healthcare personells and unemployed-retireds. When the groups having mental disorders and not having mental disorders were compared, it was found that the mean cognitive reappraisal score of the group not having mental disorders is significantly higher than that of the group having mental disorders (U: 9421.00, $\mathrm{p}<0.05)$. Results are presented in Table 3 .

In the analyses conducted to determine whether emotion suppression scores vary significantly depending on different variables, it was found that the emotion suppression scores vary significantly depending on gender ( $\mathrm{U}: 58158.50, \mathrm{p}<0.05$ ) and when the mean ranks were compared, it was concluded that the mean emotion suppression score of the male participants is higher than that of the female participants. Results are presented in Table 4.

Table 3. Evaluation of cognitive reappraisal in terms of different variables

\begin{tabular}{|c|c|c|c|c|c|c|c|}
\hline Variables & $\mathrm{n}$ & Mean \pm SD & Median & Min & Max & Mean rank & $p$-value \\
\hline Age groups & & & & & & & 0.27 \\
\hline $18-30$ years & 519 & $30.30 \pm 5.83$ & 31.00 & 6 & 42 & 434.32 & \\
\hline $31-40$ years & 181 & $30.95 \pm 6.10$ & 31.00 & 6 & 42 & 466.55 & \\
\hline 41-50 years & 124 & $29.67 \pm 6.49$ & 30.00 & 9 & 40 & 410.67 & \\
\hline$>51$ years & 50 & $30.08 \pm 5.75$ & 31.50 & 14 & 38 & 431.92 & \\
\hline Gender & & & & & & 0.67 & \\
\hline Males & 232 & $29.95 \pm 6.80$ & 31.00 & 6 & 42 & 431,49 & \\
\hline Females & 642 & $30.47 \pm 5.66$ & 31.00 & 6 & 42 & 439,67 & \\
\hline Marital status & & & & & & & 0.83 \\
\hline Single & 544 & $30.35 \pm 5.79$ & 31.00 & 6 & 42 & 436.13 & \\
\hline Married & 330 & $30.30 \pm 6.30$ & 31.00 & 6 & 42 & 439.75 & \\
\hline Education level & & & & & & & 0.10 \\
\hline Elementary-secondary & 25 & $28.56 \pm 6.81$ & 28.00 & 12 & 40 & 362.54 & \\
\hline High school & 101 & $29.33 \pm 6.91$ & 30.00 & 9 & 40 & 412.43 & \\
\hline Associate's degree & 58 & $29.50 \pm 5.47$ & 30.00 & 16 & 40 & 388.58 & \\
\hline Bachelor's degree & 597 & $30.50 \pm 5.87$ & 31.00 & 6 & 42 & 443.88 & \\
\hline Graduate degree & 93 & $31.34 \pm 5.50$ & 32.00 & 16 & 42 & 474.44 & \\
\hline Occupation & & & & & & & 0.00 \\
\hline Student & 331 & $30.63 \pm 5.38$ & 31.00 & 10 & 42 & 443.85 & \\
\hline Healthcare personnel & 187 & $29.75 \pm 5.98$ & 30.00 & 7 & 42 & 407.14 & \\
\hline Educator & 130 & $31.80 \pm 6.10$ & 30.00 & 6 & 40 & 511.09 & \\
\hline Private sector & 111 & $30.00 \pm 6.22$ & 30.00 & 6 & 40 & 423.11 & \\
\hline Public worker & 36 & $29.44 \pm 7.59$ & 31.50 & 14 & 38 & 436.10 & \\
\hline Unemployed-retired & 79 & $28.92 \pm 6.58$ & 30.00 & 12 & 40 & 383.51 & \\
\hline Health Problem & & & & & & & 0.82 \\
\hline Yes & 131 & $30.41 \pm 6.19$ & 31.00 & 11 & 42 & 442.10 & \\
\hline No & 743 & $30.32 \pm 5.95$ & 31.00 & 6 & 42 & 436.69 & \\
\hline Mental illness & & & & & & & 0.00 \\
\hline Yes & 33 & $26.87 \pm 7.03$ & 29.00 & 6 & 36 & 302.48 & \\
\hline No & 841 & $30.47 \pm 5.90$ & 31.00 & 6 & 42 & 442.80 & \\
\hline
\end{tabular}

SD - Standard Deviation 
Table 4. Evaluation of emotion suppression in terms of different variables

\begin{tabular}{|c|c|c|c|c|c|c|c|}
\hline Variables & $\mathrm{n}$ & Mean \pm SD & Median & Min & Max & Mean rank & $p$-value \\
\hline Age groups & & & & & & & 0.11 \\
\hline $18-30$ years & 519 & $15.53 \pm 4.70$ & 16.00 & 4 & 28 & 443.32 & \\
\hline $31-40$ years & 181 & $14.79 \pm 4.58$ & 15.00 & 5 & 28 & 400.00 & \\
\hline $41-50$ years & 124 & $15.62 \pm 4.56$ & 16.00 & 5 & 25 & 450.80 & \\
\hline$>51$ years & 50 & $16.16 \pm 5.07$ & 17.00 & 4 & 28 & 478.11 & \\
\hline Gender & & & & & & & 0.00 \\
\hline Males & 232 & $16.78 \pm 4.97$ & 17.00 & 4 & 28 & 507.82 & \\
\hline Females & 642 & $14.93 \pm 4.48$ & 15.00 & 4 & 26 & 412.09 & \\
\hline Marital status & & & & & & & 0.13 \\
\hline Single & 544 & $15.49 \pm 4.77$ & 16.00 & 4 & 28 & 442.57 & \\
\hline Married & 330 & $15.31 \pm 4.54$ & 15.00 & 4 & 28 & 429.15 & \\
\hline Education level & & & & & & & 0.32 \\
\hline Elementary-secondary & 25 & $17.68 \pm 4.87$ & 17.00 & 6 & 26 & 550.28 & \\
\hline High school & 101 & $15.99 \pm 5.25$ & 16.00 & 4 & 28 & 461.63 & \\
\hline Associate's degree & 58 & $15.60 \pm 3.61$ & 16.00 & 8 & 24 & 441.38 & \\
\hline Bachelor's degree & 597 & $15.29 \pm 4.71$ & 16.00 & 4 & 28 & 431.91 & \\
\hline Graduate degree & 93 & $14.95 \pm 4.28$ & 16.00 & 7 & 23 & 414.45 & \\
\hline Occupation & & & & & & & 0.52 \\
\hline Student & 331 & $15.44 \pm 4.79$ & 16.00 & 4 & 28 & 441.01 & \\
\hline Healthcare personnel & 187 & $15.69 \pm 4.38$ & 16.00 & 5 & 26 & 451.20 & \\
\hline Educator & 130 & $14.29 \pm 4.47$ & 14.00 & 2 & 45 & 376.13 & \\
\hline Private sector & 111 & $15.42 \pm 4.99$ & 16.00 & 5 & 28 & 438.64 & \\
\hline Public worker & 36 & $15.55 \pm 4.83$ & 17.00 & 4 & 24 & 454.69 & \\
\hline Unemployed-retired & 79 & $16.56 \pm 4.55$ & 16.00 & 7 & 28 & 481.92 & \\
\hline Health Problem & & & & & & & 0.95 \\
\hline Yes & 131 & $15.37 \pm 4.75$ & 16.00 & 5 & 26 & 436.32 & \\
\hline No & 743 & $15.43 \pm 4.68$ & 16.00 & 4 & 28 & 437.71 & \\
\hline Mental illness & & & & & & & 0.15 \\
\hline Yes & 33 & $16.57 \pm 5.02$ & 17.00 & 4 & 26 & 498.06 & \\
\hline No & 841 & $15.38 \pm 4.67$ & 16.00 & 4 & 28 & 435.12 & \\
\hline
\end{tabular}

SD - Standard Deviation

Table 5. Relationship between health anxiety and sub-dimensions of emotion regulation

\begin{tabular}{ccc} 
& Cognitive Reappraisal & Emotion Suppression \\
\hline Health Anxiety & $-0.13^{* *}$ & 0.04 \\
\hline$* * \mathrm{p}<0.01$ & &
\end{tabular}

When the correlation between health anxiety and emotion regulation was examined, it was found that there is a low and negative correlation between them $(\mathrm{r}=-0.13, \mathrm{p}<0.01)$. This correlation was found to be statistically insignificant $(\mathrm{r}=0.04, \mathrm{p}>0.05)$. Results are shown in Table 5.

\section{DISCUSSION}

In the current study, health anxiety scores of the participants were examined in relation to different variables. The healthy anxiety of the female participants was found to be higher than that of the male participants. This can be because of the effects of the culture, women cannot easily express their concerns. This finding seems to concur with the findings of the previous research. In their study conducted on individuals during an epidemic period in Turkey, Ekiz et al. (2020) found that health anxiety of the women is higher than that of the men. During the epidemic period, stress, anxiety and depression were found to be higher among women (Wang et al. 2020, Mazza et al. 2020). Moreover, when the literature is examined, it is seen that particularly somatoform disorders are seen more among women (Faravelli et al. 1997, Koç \& Polat 2006, Ozenli et al. 2009, Karaşar \& Oğülmüş 2016). All these findings support the finding of the current study showing that healthy anxiety is higher among the female participants.

The health anxiety of the participants aged 18-30 was found to be higher than those of the other age groups. A significant increase seen in the level of anxiety of this age group about the illness during the outbreak period might be because in this age group, people can be ill without showing any symptoms of the illness, thus, their risk of infecting other people is high. Moreover, as the individuals in this age group generally live with their families, they may feel more concerned 
about infecting their family members. In their study conducted during the outbreak period, Ekiz et al. (2020) found that the individuals in the age groups of 18-25 and 26-35 have higher anxiety levels than the other age groups, and this supports the finding of the current study.

In the current study, health anxiety was found to be higher among the university students compared to the other groups. Because of the outbreak, the education of university students was interrupted and they had to return to their families. They had to continue their education with distance education. Their lifestyle has changed dramatically. It may be thought that the students experienced health anxiety more than the other groups as a result of having various difficulties in adapting to this process. At the same time, fears of infecting family members may explain their increased health anxiety. This finding of the current study seems to be consistent with the findings reported by Wang et al. (2020), who found higher anxiety, depression and stress scores among students when compared to other people.

The healthy anxiety of the participants having physical and mental health problems was found to be higher. Since the presence of physical health problems during the outbreak may increase anxiety that the disease will be severe, health anxiety of these people might have increased. This finding concurs with the findings of the previous studies. Wang et al. (2020) found that people with weak / very poor health status and those with chronic disease had higher anxiety, depression and stress scores than those without chronic disease. Mazza et al. (2020) found that people with medical problems have high levels of anxiety and depression. In a study conducted by Unalan (2014), it was found that the health anxiety of the participants with low level of psychological problem was significantly lower than the participants with medium and high level of psychological problem.

In the current study, in the evaluation of emotion regulation in terms of various variables; the male participants were found to have emotion suppression scores than the female participants. This finding of the current study is consistent with the findings reported in the literature (Chen et al. 2005, Haga et al. 2009, Flynn et al. 2010, Demirtaş 2018). Various studies in the literature found that women express their feelings more than men (Gross \& John 2003, Kring \& Gordon 1998, Parkins 2012). In our study, the male participants' high emotion suppression scores seem to be related to the cultural roles attributed to men. The fact that men's showing their feelings of fear, anxiety and sadness is considered to be weakness from a young age may explain the high emotion suppression scores in the male participants. This finding of the study seems to be important because of the negative consequences of suppressing emotions. Gross \& John (2003) reported that suppressing emotions is associated with worse interpersonal functionality. Chen et al. (2005) pointed out that expressing emotions is considered important in terms of well-being. Traue et al. (2016) emphasized that blocking emotions is a dysfunctional coping style and has harmful consequences. Pennebaker (2009) also stated that not expressing emotions is a condition that can cause various health problems.

In the current study, the educators were found to have the highest cognitive reappraisal scores. This finding of the study can be explained by the fact that the professional roles of educators contribute to the development of their emotion regulation skills. Karabay (2019) pointed out that having effective emotion regulation skills is very important for teachers.

The cognitive reappraisal level of the group without mental disorders was found to be higher than that of the other group. This finding of the study shows that the group without mental disorders can be healthier as a result of having better emotion regulation skills. Studies have found that cognitive reappraisal is positively associated with well-being while suppressing emotions is negatively associated with well-being (Gross \& John 2003, Haga et al. 2009).

In the current study, it was found that there is a low and negative correlation between health anxiety and cognitive reappraisal. It was found that there is no correlation between emotion suppression and health anxiety. When the literature is reviewed, it is seen that there are a limited number of studies on the subject (Görgen et al. 2014, Love et al. 2018). Reiser et al. (2019) found that there is no relationship between emotion regulation and health anxiety in their research conducted on children and adolescents.

Children and adolescents were not included in the sample of this study. This situation can be considered as the limitation of the research. In the future studies, comprehensive researches on children and adolescents can be made.

\section{CONCLUSIONS}

The findings of the current study are thought to be important for psychological health protection services offered during the epidemic period. In light of these findings, following suggestions can be made:

In the study, a low and negative correlation was found between health anxiety and cognitive reappraisal. On the basis of this finding, activities directed to reappraisal can be organized to decrease anxiety in groups experiencing high levels of anxiety.

According to the results of the current study, more supportive services should be offered to the groups having the highest levels of anxiety. Given that students and young people are affected more, more mental health protective services should be offered to them. It can be important to organize online psycho-educational activities to reduce particularly students' anxiety level and to increase their psychological resilience.

The fact that men have higher emotion suppression scores than women shows that this should be taken into consideration while developing mental health services. 
In future research, men's emotion suppression can be investigated in relation to other variables. It can be thought that not expressing anxiety and fear arising from pandemic can affect men's health negatively. Therefore, it seems to be important to include activities to regulate emotions for men in mental health services so that they can express their feelings more effectively. Organization of psycho-educational programs for men to express their emotions can play an important role in the protection of men's health.

In future studies, variables such as depression, anxiety disorder and post-trauma stress disorder can be explored in more detail.

\section{Acknowledgements: None.}

\section{Conflict of interest : None to declare.}

\section{Contribution of individual authors:}

Derya Canlı: study design, data collection, literature review, first draft, approval of the final version.

Burcu Karaşar: study design, data collection, statistical analysis, approval of the final version.

\section{References}

1. Aldao A, Nolen-Hoeksema $S$ \& Schweizer S: Emotion regulation strategies across psychopathology: a metaanalytic review. Clin Psychol Rev 2010; 30:217- 37

2. Anderson R, Saulsman L, Nathan P: Helping Health Anxiety. Perth, Western Australia: Centre for Clinical Interventions, 2011

3. Asmundson GJG \& Fergus TA: The Concept of Health Anxiety. In Erik HL (eds): The Clinician's Guide to Treating Health Anxiety. 1-18. Academic Press, 2019

4. Aydemir Ö, Kırkpınar İ, Satı T, Uykur B, Cengisiz C: Reliability and Validity of the Turkish Version of the Health Anxiety Inventory. Noro Psikiyatr Ars 2013; 50:325-331

5. Ceçen AR: Duygular insan yaşamında neden vazgeçilmez ve önemlidir?. Çukurova Univ Sosyal Bil Enst Derg 2002; 9:164-170. (Turkish)

6. Chen SX, Cheung FM, Bond MH, Leung JP: Decomposing the construct of ambivalence over emotional expression in a Chinese cultural context. Eur J Pers 2005; 19:185-204

7. D'Avanzato C, Joormann J, Siemer M, Gotlib IH: Emotion regulation in depression and anxiety: Examining diagnostic specificity and stability of strategy use. Cogn Ther Res 2013; 37:968-980

8. Demirtaş AS: The predictive roles of emotion regulation strategies and self-esteem on happiness. J Turkish Sci Educ 2018; 13:487-503

9. Kring $A M$ \& Gordon AH: Sex differences in emotion: Expression, experience, and physiology. J Pers Soc Psychol 1998; 74:686-703

10. Ekiz T, Illman E, Dönmez E: Comparison Of Health Anxiety Level And Control Perception Of Covid-19. Usaysad Derg 2020; 6:139-154

11. Faravelli C, Salvatori S, Galassi F, Aiazzi L, Drei C, Cabras P: Epidemiology of somatoform disorders: a community survey in florence. Soc Psychiatry Psychiatr Epidemiol 1997; 32:24-29

12. Flynn J, Hollenstein T, Mackey A: The effect of suppressing and not accepting emotions on depressive symptoms: Is suppression different for men and women?. Pers Individ Differ 2010; 49:582-586

13. Ghanizadeh A \& Firoozabadi A: Review Of Somatoform Disorders In Dsm-Iv And Somatic Symptom Disorders in Proposed Dsm-V. Psychiatr Danub 2012; 24:353-358

14. Görgen SM, Hiller W, Witthöft M: Health anxiety, cognitive coping, and emotion regulation: a latent variable approach. Int J Behav Med 2014; 21:364-74

15. Gross JJ: Antecedent- and response-focused emotion regulation: Divergent consequences for experience, expression, and physiology. J Pers Soc Psychol 1998a; 74:224-237

16. Gross JJ: The emerging field of emotion regulation: an integrative review. Rev Gen Psychol 1998b; 2:271-299

17. Gross JJ \& John OP: Individual differences in two emotion regulation processes: implications for affect, relationships, and well-being. J Pers Soc Psychol 2003; 85:348-62

18. Haga SM, Kraft P, Corby EK: Emotion Regulation: Antecedents and well-being outcomes of cognitive reappraisal and expressive suppression in Cross-cultural samples. J Happiness Stud 2009; 10:271-291

19. Harrison A, Sullivan S, Tchanturia K, Treasure J: Emotional functioning in eating disorders: attentional bias, emotion recognition and emotion regulation. Psychol Med 2010; 40:1887-1897

20. Hopwood CJ, Schade N, Matusiewicz A, Daughters SB, Lejuez CW: Emotion regulation promotes persistence in a residential substance abuse treatment. Subst Use Misuse 2015; 50:251-256

21. Jakovljevic M: COVID-19 Crists As A Collectıve Hero's Journey To Better Public And Global Mental Health. Psychiatr Danub 2020; 32:3-5

22. Jakovljevic M, Bjedov S, Jaksic N, Jakovljevic I: COVID19 pandemia and public and global mental health from the perspective of global health security. Psychiatr Danub 2020; 32:6-11

23. John OP \& Gross JJ: Healthy and unhealthy emotion regulation: personality processes, individual differences, and life span development. J Pers 2004; 72:1301-33

24. Joormann J, Gotlib IH: Emotion regulation in depression: relation to cognitive inhibition. Cogn Emot 2010; 24:281-98

25. Karabay SO: Emotion regulation, teaching beliefs and child-teacher relationships from the perspectives of preschool teachers. Education 2019; 3-13:101-115

26. Karaşar $B$ \& Öğ̈̈̈müş $S$ : Üniversite öğrencilerinde sosyal onay ihtiyacı ve psikolojik belirtilerin çeşitli değişkenlere göre incelenmesi. Sakarya Univ Eğitim Fak Derg 2016; 32:97-121. (Turkish)

27. Kırkpınar I, Deveci E, Kılıç A, Camur DZ: Somatization disorder and hypochondriasis: as like as two peas?. Anatolian J Psychiatr 2016; 17:165-173

28. Koç $M$ \& Polat $\ddot{U}$ : The mental health of university students. J Hum Sci 2006; 3

29. Lee M\& You M: Psychological and Behavioral Responses in South Korea During the Early Stages of Coronavirus Disease 2019 (COVID-19). Int J Environ Res Public Health 2020; 17:E2977 
30. Li S, Wang Y, Xue J, Zhao N, Zhu T: The Impact of COVID-19 Epidemic Declaration on Psychological Consequences: A Study on Active Weibo Users. Int J Environ Res Public Health 2020; 17:2020

31. Love $S$, Sharman $R$, Kannis-Dymand L: Emotion regulation and the specific associations with health anxiety. Psychol Stud 2018; 63:410-418

32. Macklem GL: Practitioners's guide to emotion regulation in school-aged children. Springer Books, USA, 2010

33. Marčinko D, Jakovljević $M$, Jakšić N, Bjedov S, Drakulić AM: The importance of psychodynamic approach during COVID-19 Pandemic. Psychiatr Danub 2020; 32:15-21

34. Martin RC \& Dahlen ER: Cognitive emotion regulation in the prediction of depression, anxiety, stress, and anger. Pers Individ Differ 2005; 39:1249-1260

35. Mazza C, Ricci E, Biondi S, Colasanti M, Ferracuti S, Napoli C et al.: Nationwide Survey of Psychological Distress among Italian People during the COVID-19 Pandemic: Immediate Psychological Responses and Associated Factors. Int J Environ Res Public Health 2020; 17:E3165

36. Omran MP: Relationships between cognitive emotion regulation strategies with depression and anxiety. Open $J$ Psychiatry 2011; 1:106-109

37. Ozenli Y, Yoldaşcan E, Topal K, Özçürümez G: Prevalence and associated risk factors of somatization disorder among Turkish university students at an education faculty. Anatolian J Psychiatr 2009; 10:131-136

38. Parkins R: Gender and emotional expressiveness: an analysis of prosodic features in emotional expression. Griffith Work Papers Pragmat Intercult Commun, 46-54. Griffith University Press, 2012

39. Pennebaker JW: İçinizi Dökün. Duyguları Dişavurmanın İyileştirici Gücü. Ankara: Ankara: Hyb Press, 2009. (Turkish)

40. Reiser SJ, Oliver AM, Power HA, Wright KD: Health anxiety and emotion regulation in children and adolescents: is there a relationship?. J Child Health Care 2019; 49:168-183

41. Ruscitti C, Rufino K, Goodwin N, Wagner R. Difficulties in emotion regulation in patients with eating disorders. Borderline Personal Disord Emot Dysregul 2016; 3:3

42. Salkovskis PM, Rimes KA, Warwick HM, Clark DM: The Health Anxiety Inventory: development and validation of scales for the measurement of health anxiety and hypochondriasis. Psychol Med 2002; 32:843-53

43. Shoutham-Gerow MA: Emotion regulation in children and adolescents a practitioner's guide. New York: Guildford Press, 2013

44. Sunderland M, Newby $J M \&$ Andrews G: Health anxiety in Australia: prevalence, comorbidity, disability, and service use. Br J Psychiatry 2013; 202:56-61

45. Thompson RA: Emotion regulation: a theme in search of definition. Monogr Soc Res Child Dev 1994; 59:25-52

46. Totan T: Validity And Reliability of the Turkish Form of the Emotion Regulation Questionnaire. J Cogn Psychother 2015; 3:153-161

47. Traue HC, Kessler H, Deighton RW: Emotion and Inhibition. In G Fink (ed): Concepts, Cognition, Emotion, and Behavior, 233-240. San Diego, CA: Academic Press, 2016

48. Unalan E: Üniversite Öğrencilerinde Ruh Sağlı̆̆ı, Sağllk Kaygısı Ve Sağlık Davranışları Arasındaki İlişkiler. Doctoral Thesis, İstanbul, Okan Univ Social Sci Inst Derg 2014. (Turkish)

49. Wang C, Pan R, Wan X, Tan Y, Xu L, Ho CS et al.: Immediate Psychological Responses and Associated Factors during the Initial Stage of the 2019 Coronavirus Disease (COVID-19) Epidemic among the General Population in China. Int J Environ Res Public Health 2020; 17:1729

50. Weinbach N, Sher H, Bohon C. Differences in Emotion Regulation Difficulties Across Types of Eating Disorders During Adolescence. J Abnorm Child Psychol 2018; 46:1351-1358
Correspondence:

Derya Canl, $M D$

Department of Psychiatry, Amasya University

Sabuncuoğlu Şerefeddin Training and Research Hospital

Amasya, Turkey

E-mail:derya.canli03@gmail.com 